\title{
MFI-type zeolite membrane on hollow fiber substrate for hydrogen separation
}

\author{
YUAN WenHui ${ }^{1 *}$, WANG DeLin ${ }^{1} \& \mathrm{LI} \mathrm{Li}^{2}$ \\ ${ }^{1}$ School of Chemistry and Chemical Engineering, South China University of Technology, Guangzhou 510640, China; \\ ${ }^{2}$ College of Environmental Science and Engineering, South China University of Technology, Guangzhou 510640, China
}

Received August 23, 2010; accepted November 19, 2010

\begin{abstract}
High performance MFI-type zeolite membranes on the outer surface of $\alpha-\mathrm{Al}_{2} \mathrm{O}_{3}$ hollow fibers were synthesized by secondary growth method using pure silica sol without an organic template. X-ray diffraction was used to characterize the phase structure of both the seed layer and zeolite membrane. The morphologies of the seed layer and zeolite membrane were examined by scanning electron microscopy. The zeolite membrane achieved an extraordinary $\mathrm{H}_{2} / \mathrm{CO}_{2}$ separation factor of 10 with a high $\mathrm{H}_{2}$ permeance of $5.56 \times 10^{-7} \mathrm{~mol} \mathrm{~m}^{-2} \mathrm{~s}^{-1} \mathrm{~Pa}^{-1}$ at $723 \mathrm{~K}$.
\end{abstract}

MFI membrane, $\alpha-\mathrm{Al}_{2} \mathrm{O}_{3}$ hollow fiber, $\mathrm{H}_{2}$ permeance, separation factor

Citation: Yuan W H, Wang D L, Li L. MFI-type zeolite membrane on hollow fiber substrate for hydrogen separation. Chinese Sci Bull, 2011, 56: 2416-2418, doi: 10.1007/s11434-011-4599-4

Zeolite membranes have attracted increasing interest because of their important potential applications in several areas [1]. MFI type zeolite membranes have potential for $\mathrm{H}_{2}$ separation [2]. In recent years, several research groups have synthesized good quality zeolite membranes without mesoand macroporous defects on disks [3] or tube substrates. However, reports of synthesis of good quality MFI-type zeolite membranes on hollow fibers are rare.

Liu et al. [4] reported the critical factors in synthesis of oriented MFI zeolite films. Seeding on the support is a crucial processing factor for synthesis of high-performance zeolite membrane [5-7]. Caro et al. [8] reported charging the support surface by $\mathrm{pH}$ control to achieve opposite charges on the seeds and support, which was then used for attachment by electrostatic attraction. This method makes it easy to obtain a uniform seed distribution, and continuous zeolite membranes can be prepared with high reproducibility.

In this paper, good quality MFI-type zeolite membranes were prepared on $\alpha-\mathrm{Al}_{2} \mathrm{O}_{3}$ hollow fibers by the secondary

\footnotetext{
*Corresponding author (email: cewhyuan@scut.edu.cn)
}

growth method using pure silica sol without an organic template. We charged the support surface by $\mathrm{pH}$ control in a similar manner to Caro et al. [8]. We designed the synthesis strategy and method to avoid the template removal step. Firstly, nanosized silicalite powder was prepared by hydrothermal synthesis of a solution of $1 \mathrm{~g}$ of fumed silica, $5 \mathrm{~mL}$ $\left(1 \mathrm{~mol} \mathrm{~L}{ }^{-1}\right)$ of TPAOH, and $0.07 \mathrm{~g}$ of $\mathrm{NaOH}$ at $120^{\circ} \mathrm{C}$ for $12 \mathrm{~h}$. The crystals were purified by repeated centrifugation washes with deionized water. A stable seed sol was prepared from the silicalite powder $(0.5 \mathrm{~g}), 14 \mathrm{~mL}$ of $0.5 \%$ hydroxy propylcellulose (HPC) $\left(M=100000 \mathrm{~g} \mathrm{~mol}^{-1}\right)$ solution, and $33 \mathrm{~mL}$ of deionized water. The $\mathrm{pH}$ of this solution was adjusted from about 10 to $3-4$ by addition of $\mathrm{HNO}_{3}$ $\left(1 \mathrm{~mol} \mathrm{~L}{ }^{-1}\right)$. A continuous zeolite layer was coated on a porous $\alpha-\mathrm{Al}_{2} \mathrm{O}_{3}$ hollow fiber by dip-coating the hollow fiber in the $\mathrm{pH}$-adjusted seed solution. The supported seed layer was dried at $40^{\circ} \mathrm{C}$ for $2 \mathrm{~d}$ and calcined at $450^{\circ} \mathrm{C}$ for $8 \mathrm{~h}$ to remove the template. It was then placed in a template-free silicalite synthesis solution of $0.16 \mathrm{~g}$ of $\mathrm{NaOH}, 1 \mathrm{~g}$ of fumed silica, and $10.5 \mathrm{~g}$ of $\mathrm{H}_{2} \mathrm{O}$ at $180^{\circ} \mathrm{C}$ for $4 \mathrm{~h}$, and then dried at $40^{\circ} \mathrm{C}$ for $2 \mathrm{~d}$.

X-ray diffraction spectra of powders obtained from 
crushed fibers after dip-coating and secondary growth are shown in Figure 1. Both the seed layer and zeolite membrane exhibited peaks characteristic of MFI-type zeolite between $5-25^{\circ}$, which indicates that the seed layer and membrane are pure MFI phase.

Scanning electron microscopy showed the outer diameter of the hollow fiber was about $1.8 \mathrm{~mm}$, and the inner diameter was about $1.6 \mathrm{~mm}$ (Figure 2(a)). The micrographs of the surface of the seed layer (Figure 2(b)) and the zeolite membrane (Figure 2(c)) showed a uniform seed layer was obtained by dip-coating, and the grains after secondary growth were intergrown. As seen in micrograph (d), the zeolite membrane was about $3 \mu \mathrm{m}$ thick.

The Al and Si concentrations on the surface of the zeolite membrane were analyzed by energy dispersive X-ray spectrometry (EDX). The zeolite membrane had an Al/Si ratio of 0.031 , which is slightly lower than that reported by Pan et al. [9].

In single gas permeation tests, the sweep gas (He) flow

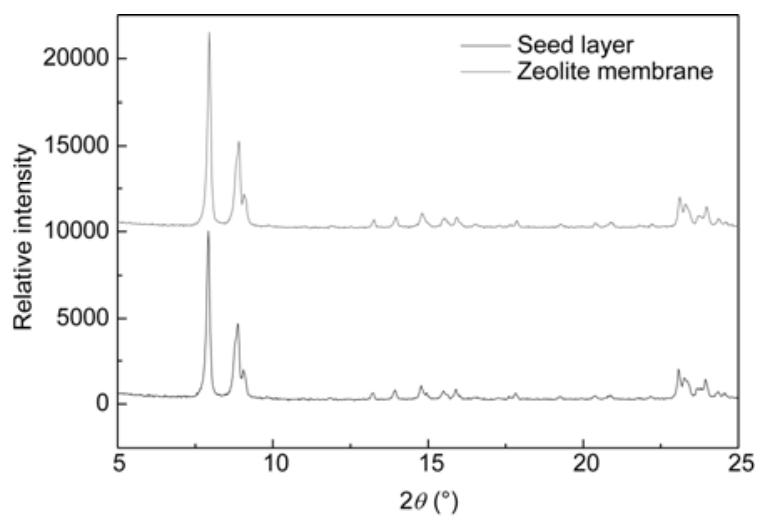

Figure 1 X-ray diffraction patterns of calcined silicalite seed layer and zeolite membrane.

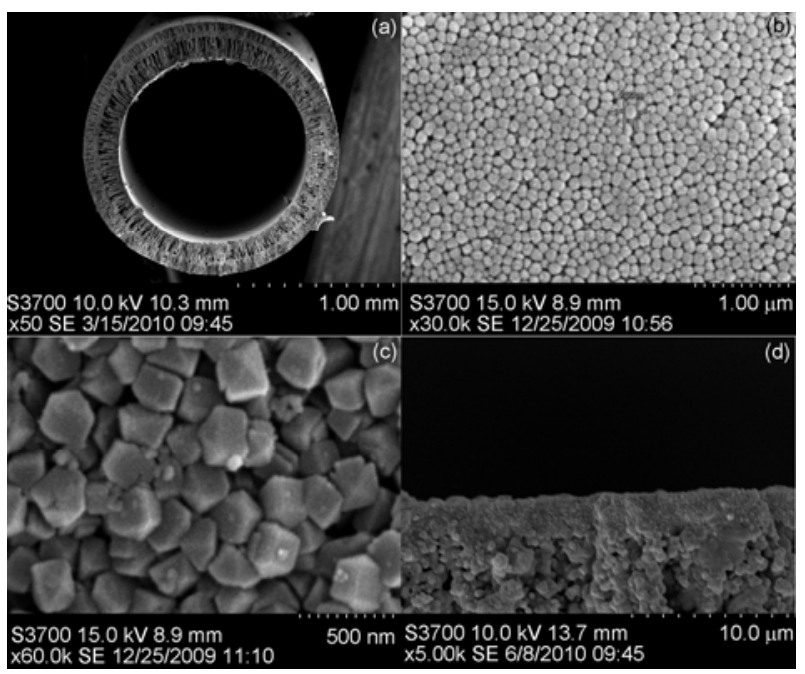

Figure 2 Scanning electron micrographs of (a) $\alpha-\mathrm{Al}_{2} \mathrm{O}_{3}$ hollow fiber, (b) calcined silicalite seed layer, (c) MFI-type zeolite membrane after secondary growth, (d) cross-section of the zeolite membrane. rate was $15 \mathrm{~cm}^{3} \mathrm{~min}^{-1}$ and the feed flow rate was $23 \mathrm{~cm}^{3}$ $\min ^{-1}$. The permselectivity of $\mathrm{H}_{2} / \mathrm{SF}_{6}$ and $\mathrm{H}_{2} / \mathrm{n}-\mathrm{C}_{4} \mathrm{H}_{10}$ were 152 and 125 (Table 1), respectively, at $298 \mathrm{~K}$. These results are much larger than their Knudsen values of 8.54 and 5.38, and indicate the zeolite membrane is good quality. Furthermore, the permselectivity of $\mathrm{H}_{2}$ over $\mathrm{CO}_{2}$ was about 5.4 at $298 \mathrm{~K}$. At $473 \mathrm{~K}$ this reduced to about 5.2, which is still larger than the Kundsen selectivity. These results show that the gas permeation is dominated by a molecular sieving mechanism for the zeolite membranes.

Figure 3 shows the temperature dependency of gas permeance for the MFI-type zeolite membrane at 298-723 K. In the separation of $\mathrm{H}_{2} / \mathrm{CO}_{2}$ mixtures, the total feed flow rate was $45 \mathrm{~cm}^{3} \mathrm{~min}^{-1}$ and the He sweep flow rate was 33.5 $\mathrm{cm}^{3} \mathrm{~min}^{-1}$. At $298 \mathrm{~K}$, the MFI membrane was selective toward $\mathrm{CO}_{2}$ and had low $\mathrm{H}_{2}$ permeance because the preferentially adsorbed $\mathrm{CO}_{2}$ limited the access of $\mathrm{H}_{2}$ molecules to the zeolite pores. As the temperature increased, the $\mathrm{H}_{2}$ permeance increased and the $\mathrm{CO}_{2}$ permeance decreased until the membrane transitioned from being $\mathrm{CO}_{2}$-selective to $\mathrm{H}_{2}$-selective at about $380 \mathrm{~K}$. The flux of $\mathrm{H}_{2}$ was about $5.56 \times 10^{-7} \mathrm{~mol} \mathrm{~m}^{-2} \mathrm{~s}^{-1} \mathrm{~Pa}^{-1}$ at $723 \mathrm{~K}$, which is larger than flux of $\mathrm{H}_{2}$ on tube substrate [10], and the separation factor of $\mathrm{H}_{2}$ over $\mathrm{CO}_{2}$ was about 10 at $723 \mathrm{~K}$.

In conclusion, $\mathrm{pH}$ control was used to create opposite charges on the seed and support, which allowed formation of a uniform seed layer. MFI type zeolite membranes were synthesized on $\alpha-\mathrm{Al}_{2} \mathrm{O}_{3}$ hollow fiber with good reproducibility. Permselectivities of $\mathrm{H}_{2} / n-\mathrm{C}_{4} \mathrm{H}_{10}$ and $\mathrm{H}_{2} / \mathrm{SF}_{6}$ on the MFI-type zeolite membrane were ideal at 125 and 152 at $298 \mathrm{~K}$, which indicates the zeolite membranes are defect

Table 1 Permeance $\left(\times 10^{-7} \mathrm{~mol} \mathrm{~m}^{-2} \mathrm{~s}^{-1} \mathrm{~Pa}^{-1}\right)$ of single gases on the zeolite membrane at 298 and $473 \mathrm{~K}$

\begin{tabular}{ccccccc}
\hline Temperature $(\mathrm{K})$ & $\mathrm{H}_{2}$ & $\mathrm{CO}_{2}$ & $n-\mathrm{C}_{4} \mathrm{H}_{10}$ & $\mathrm{SF}_{6}$ & $\alpha_{\mathrm{H}_{2} / n-\mathrm{C}_{4} \mathrm{H}_{\mathrm{l0}}}$ & $\alpha_{\mathrm{H}_{2} / \mathrm{SF}_{6}}$ \\
\hline 298 & 6.38 & 1.18 & 0.051 & 0.042 & 125 & 152 \\
473 & 7.23 & 1.39 & 0.087 & 0.075 & 83 & 96.4 \\
\hline
\end{tabular}

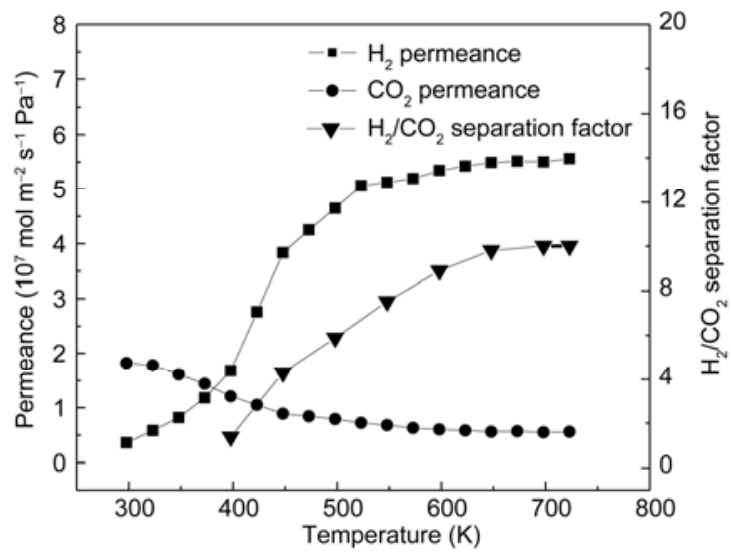

Figure 3 Permeance of an equimolar $\mathrm{H}_{2} / \mathrm{CO}_{2}$ mixture on MFI type zeolite membrane as a function of temperature. 
free. The resultant zeolite membrane achieved an extraordinary $\mathrm{H}_{2} / \mathrm{CO}_{2}$ separation factor of 10 with a high $\mathrm{H}_{2}$ permeance of $5.56 \times 10^{-7} \mathrm{~mol} \mathrm{~m}^{-2} \mathrm{~s}^{-1} \mathrm{~Pa}^{-1}$ at $723 \mathrm{~K}$.

This work was supported by the National Natural Science Foundation of China (20976057).

1 Zhou M, Zhang B Q, Liu X F. Chinese Sci Bull, 2008, 53: 801-816

2 Dong J H, Lin Y S, Kanezashi M, et al. J Appl Phys, 2008, 104: 121301-121317
3 Dong Q, Huang P, Xu N P, et al. J Chem Engin Chinese Univ, 2001, 15: 179-182

4 Liu X F, Zhang B Q, Lin Y S. Synthesis of oriented MFI zeolite films by template-free secondary growth. Chin J Inorg Chem, 2008, 24: 1679-1685

5 Yuan W H, Lin Y S, Yang W S. J Am Chem Soc, 2004, 126: 4776-4777

6 Lai Z P, Bonilla G, Diaz I, et al. Science, 2003, 300: 456-460

7 Wang Z B, Ge Q Q, Shao J, et al. J Am Chem Soc, 2009, 131: 6910-6911

8 Caro J, Noack M. Microp Mesop Mater, 2008, 115: 215-233

9 Pan M, Lin Y S. Microp Mesop Mater, 2001, 43: 319-327

10 Tang Z, Dong J H, Nenoff T M. Langmuir, 2009, 25: 4848-4852

Open Access This article is distributed under the terms of the Creative Commons Attribution License which permits any use, distribution, and reproduction in any medium, provided the original author(s) and source are credited. 